\title{
ASPECTOS DO PROCESSO DE CONSTRUÇÃO DO TRABALHO DE CONCLUSÃO DE CURSO NA MODALIDADE A DISTÂNCIA: perspectivas dos alunos, tutores e professores orientadores
}

\author{
Nádia Brunetta, EA/UFRGS, nabrunetta@yahoo.com.br \\ Elaine Di Diego Antunes, EA/UFRGS, elaine.antunes@ufrgs.br \\ Diogo Joel Demarco, EA/UFRGS, diogo.demarco@ufrgs.br \\ Ivan Antônio Pinheiro, EA/UFRGS, iapinheiro@ea.ufrgs.br
}

\begin{abstract}
Resumo
O presente trabalho objetiva apresentar as perspectivas dos alunos, tutores e professores orientadores acerca do processo de construção do trabalho de conclusão de curso na modalidade a distância, através de uma pesquisa realizada nos cursos de graduação em Administração e especialização em Negociação Coletiva ofertados pela Escola de Administração da UFRGS. Adotou-se a estratégia de estudos de casos múltiplos, sendo que os dados foram coletados através de questionários e entrevistas e foram interpretados com base na análise de conteúdo. Dentre os principais resultados apresentados pelos alunos para a elaboração do trabalho final, destacam-se: escassez de tempo para conciliar as atividades do curso com outros compromissos; dificuldade de compreensão e de uso das normas técnicas; problemas de relacionamento com tutores e professores orientadores, sob a alegação de que a distância física interferiria de forma prejudicial no processo de orientação; dificuldade em redigir textos científicos; obstáculos para acesso ao campo de pesquisa e para o acesso a materiais bibliográficos, entre outros. Os professores orientadores e tutores, por sua vez, sugeriram novas possibilidades de atuação para minimizar as dificuldades e otimizar o processo de construção do trabalho de conclusão de curso.
\end{abstract}

Palavras-chave: alunos, tutores, professores orientadores, ensino a distância, trabalho de conclusão de curso.

\begin{abstract}
This paper aims to present the views of students, tutors and academic advisers regarding the process of putting together the final paper in a distance learning course, as shown by a survey carried out in the undergraduate degree in Management and specialization in Collective Bargaining offered by the Management School of UFRGS. A multiple case study approach was adopted. The data were collected by means of questionnaires and interviews and interpreted using content analysis. Among the main points raised by the students regarding the preparation of the final paper were: lack of time to reconcile course activities with other commitments; difficulty understanding and using technical standards, relationship problems with tutors and academic advisers, on the grounds that the physical distance hampers the process of supervision; difficulty in writing scientific texts; obstacles inhibiting access to the field research and to bibliographic materials, among others. Teachers and tutors, in turn, suggested new forms of intervention to minimize the difficulties and optimize the process of preparing the final paper.
\end{abstract}

Key-words: Students; tutors; orientating teachers; distance learning; course final paper. 


\section{INTRODUÇÃO}

Devido ao crescente número de interessados e adeptos a cursos ofertados na modalidade a distância, diversas pesquisas acerca desta temática têm sido desenvolvidas nacional e internacionalmente. Discussões pedagógicas, desenvolvimento e utilização de materiais interativos e novos modelos de ambientes virtuais de aprendizagem (AVAs) têm sido apresentados como possibilidades de melhoria e incremento da área. Tais condições impulsionam também o desenvolvimento de estudos acerca dos processos que possibilitam a formação dos alunos que buscam cursos nesta modalidade de ensino. Neste contexto, busca-se responder à seguinte questão de pesquisa: quais são os principais aspectos relativos ao processo de construção do trabalho de conclusão de curso na modalidade a distância, na opinião dos alunos, tutores e professores orientadores? Para responder esta questão, foi realizada uma pesquisa com atores envolvidos nos cursos EAD de graduação em Administração (período de 2006 a 2010) e especialização em Negociação Coletiva (período de 2009 a 2011), ofertados pela Escola de Administração da UFRGS. Nestes cursos a orientação do TCC é individual, personalizada e a distância, realizada pelo professor orientador da área, com apoio do tutor, que media o processo.

A justificativa deste estudo refere-se ao fato de promover uma reflexão pedagógica para potencializar o trabalho colaborativo e a interação entre os partícipes do processo, retomando as discussões conceituais de ensino e aprendizagem, que subsidiam a orientação e acompanhamento da elaboração do TCC. Esta reflexão permitirá uma avaliação que poderá oportunizar um olhar para novas formas de ação, visando à proposição de diretrizes que possibilitem à melhoria do processo de orientação dos trabalhos de conclusão de cursos ofertados a distância, considerando que estudos neste campo ainda são incipientes. Para tanto, propõe-se como objetivo geral desta pesquisa: identificar e analisar as perspectivas dos alunos, tutores e professores orientadores acerca do processo de construção do trabalho de conclusão de curso na modalidade a distância, através de um estudo realizado nos cursos de graduação em Administração e especialização em Negociação Coletiva ofertados pela Escola de Administração da UFRGS. Esta apresentação introduz o tema da pesquisa, apresenta sua problematização, justificativa e objetivos. No item seguinte é apresentado brevemente o referencial teórico utilizado. O método empregado para a realização da pesquisa é descrito na sequência. Após são apresentados os principais resultados da pesquisa e, para concluir, seguem as considerações finais do estudo.

\section{QUADRO TEÓRICO: os papéis do docente e do tutor em EAD}

Neste bloco são apresentados os aspectos conceituais que embasam os papéis do docente e do tutor no ensino a distância.

\subsection{Papel do docente em EAD}

A docência envolve todas as atividades desenvolvidas pelos professores visando a formação de seus alunos, estas atividades estão relacionadas a conhecimentos, saberes, fazeres e com relações interpessoais de cunho afetivo, valorativo e ético, revelando que estas não se esgotam na dimensão técnica, mas remetem ao que há de pessoal em cada professor (ISAIA, 2006). O docente universitário preocupa-se com a produção e é atuante em atividades de ensino, pesquisa e extensão; portanto, suas atividades devem estar pautadas em situações próprias do contexto, como indica Cachapuz (2002) ao explicar a docência no ensino universitário como uma atividade complexa do ponto de vista intelectual e que envolve conhecimentos específicos, incluindo saberes didáticopedagógicos, que podem ser apropriados e desenvolvidos, quando se leva em 
consideração as especificidades de contextos sociais e de trabalho, o perfil e as expectativas dos docentes.

Muitas vezes, a docência é vista com certo reducionismo, sendo tratada simplesmente como as atividades que os professores realizam quando estão atuando em sala de aula ou, no contexto desta pesquisa, envolvidos em atividades de EAD. García (apud PACHANE, 2006) aponta que em contextos universitários, a docência não pode se restringir à atuação em sala de aula, o docente deveria incluir situações que interferem nas decisões de como, quando e por quem vai ser transmitido o conteúdo, apresentando seus objetivos e finalidades, assim, seriam desenvolvidas atividades para assegurar a aprendizagem. Uma concepção da atividade docente a partir desta perspectiva traz repercussões para o professor e para sua avaliação, na medida em que os conhecimentos e competências que os docentes devem demonstrar e dominar não se referem exclusivamente à interação direta com os alunos. Lévy (1999) afirma que o papel do professor estará centrado mais no acompanhamento e na gestão das aprendizagens, incitando a troca de saberes, fazendo a mediação relacional, simbólica e personalizada dos percursos de aprendizagem; o docente será um animador da inteligência coletiva dos grupos que estão ao seu encargo. Estas descrições remetem, no entanto, também ao papel do tutor, considerando que são estes que atuam na linha de frente dos cursos e interagem diretamente com os grupos de alunos dos programas de EAD em grande parte das instituições de ensino superior brasileiras.

$\mathrm{O}$ fato de nem sempre existir um horário fixo ou pré-estipulado nas atividades de ensino realizadas em cursos EAD, podendo estas serem realizadas em espaços distintos e tempos diversos, o professor deve exercer um papel de estimulador e incentivador do aluno no desenvolvimento das tarefas previstas. Em muitos casos, os alunos se sentem "sozinhos" no processo e acabam desistindo do curso, aumentando a evasão, que é bastante comum em cursos a distância. Para minimizar esta ocorrência, momentos dinâmicos (como a realização de chats entre os alunos e professores) devem ser promovidos não apenas para discutir os conteúdos programáticos, mas também para promover o estreitamento da relação entre os atores envolvidos no processo (LEAL, 2007). É inegável, portanto, que apesar de delimitados, os papéis dos tutores e professores orientadores se misturem no cotidiano dos cursos ofertados na modalidade EAD, como contextualizado a seguir.

\subsection{O papel do tutor em EAD}

Belloni (2003) apresenta o tutor como profissional que orienta os alunos em seus estudos, esclarece dúvidas e explica questões relativas ao conteúdo da disciplina; em geral, os tutores participam também das atividades de avaliação dos cursos. Enquanto o docente cria propostas de atividades para reflexões, o tutor proporciona apoio à resolução de exercícios, sugere fontes de informação alternativas, oferece explicações e favorece o processo de compreensão dos conteúdos.

Para atender aos objetivos de mediação do conhecimento e interação, requisitos comuns em cursos de EAD, o acompanhamento tutorial torna-se elemento fundamental, assegura o desenvolvimento e o aproveitamento dos eventos realizados em cursos nesta modalidade. Assim, o sistema de tutoria, muito mais que um aspecto estrutural e de apoio ao estudante, é visto como o atendimento à educação individualizada e colaborativa, isto é, como uma estratégia de abordagem pedagógica centrada no ato de aprender, que põe à disposição do estudante todos os recursos que irão permitir a consecução dos objetivos previstos no curso, desenvolvendo nos alunos uma maior autonomia em seu percurso de aprendizagem. Nesta perspectiva, a função dos tutores é de promover a aprendizagem, através de um processo de diálogo onde o conhecimento é 
produzido a partir deste movimento, entre tutores, professores, alunos, avaliação e conteúdos (NEVADO, 2005).

Cabe ainda destacar que, sendo as atividades de EAD mediadas por tecnologias de comunicação, muitas vezes o computador é o meio de comunicação que o aluno utiliza para desabafar, apontar fragilidades do sistema e apresentar as dificuldades enfrentadas no dia a dia, portanto, o tutor precisa ser capaz de identificar tais emoções e lidar com elas. O tutor precisa também procurar identificar maneiras de proporcionar apoio motivacional para aqueles alunos que demonstram fragilidades ou demandam uma atenção maior, ele tem o papel de fazer com que todos os alunos sintam-se motivados no processo, mas que também percebam a necessidade de serem independentes (MOORE e KEARSLEY, 2007).

Em situações de educação a distância, a interação entre professores-alunos, tutores alunos e alunos-alunos é um fator extremamente importante e eficaz no processo de ensino-aprendizagem. Belloni (2003) ressalta a importância deste mediador, seja ele tutor ou professor, e que é fundamental que esse mediador esteja em constante diálogo com seus alunos, com o objetivo de estimulá-los durante todo o processo e principalmente mostrar que não estão sozinhos, contribuindo para que não desistam do processo de formação, consequentemente minimizando o índice de evasão. Um ponto importante a ser considerado pelas equipes de coordenação de curso é o fato de que os tutores precisam descobrir sozinhos as limitações e o potencial da tecnologia, além das melhores técnicas para comunicação (MOORE; KEARSLEY, 2007), por tratarem de alunos com perfis diferentes, distribuídos de forma aleatória em grupos, para gerenciamento (de cada tutor).

\subsection{O Papel do aluno em EAD}

Para Moran (2007), a educação avança pouco nas organizações empresariais e nas escolas porque ainda estamos profundamente inseridos em organizações autoritárias, em processos de ensino e aprendizagem controladores, com educadores pouco livres, mal resolvidos, que repetem mais do que pesquisam, que impõem mais do que se comunicam, que não acreditam no seu próprio potencial nem no dos seus alunos e que desconhecem o quanto eles e seus alunos podem realizar.

A EAD também pode ser considerada estimuladora da autonomia do aluno, no sentido em que a distância física existente entre os atores do processo de ensino e aprendizagem possibilita aos alunos o desenvolvimento da habilidade de gerenciamento do tempo e aprendizado, já que precisam estabelecer e planejar períodos de estudo e organizar a prioridade dos conteúdos a serem estudados (PASSARELLI, 2007). Neste sentido, Freire (1996, p. 23) complementa que "não há docência sem discência, as duas se explicam e seus sujeitos, apesar das diferenças que os conotam, não se reduzem à condição de objeto um do outro". Percebe-se, assim, a importância do papel do educador e a certeza de que faz parte da sua tarefa docente não apenas ensinar os conteúdos, mas também ensinar a pensar certo.

A construção ou a produção do conhecimento do objeto implica o exercício da curiosidade, sua capacidade crítica de "tomar distância" do objeto, de observá-lo, de delimitá-lo, de cindi-lo, de "cercar" o objeto ou fazer sua aproximação metódica, sua capacidade de comparar, de perguntar. Estimular a pergunta, a reflexão crítica sobre a própria pergunta, o que se pretende com esta ou com aquela pergunta em lugar da passividade em face das explicações discursivas do professor, espécies de respostas e perguntas que não foram feitas. Isto não significa realmente que devamos reduzir a atividade docente em nome da defesa da curiosidade necessária, a puro vai-e-vem de perguntas e 
respostas, que burocraticamente se esterilizam. A dialogicidade não se nega a validade de momentos explicativos, narrativos, em que o professor expõe ou fala do objeto. O fundamental é que o professor e alunos saibam que a postura deles, do professor e dos alunos, é dialógica, aberta, curiosa, indagadora e não apassivada, enquanto fala ou enquanto ouve. O que importa é que o professor e os alunos se assumam epistemologicamente curiosos (FREIRE, 1996 p. 85).

Portanto, o professor tem um papel fundamental no desenvolvimento e exercício da autonomia do aluno partindo da condição de que "saber que ensinar não é transferir conhecimento, mas criar as possibilidades para a sua própria produção ou a sua construção" (FREIRE, 1996 p. 47). No item seguinte são apresentados os procedimentos metodológicos utilizados nesta pesquisa.

\section{PROCEDIMENTOS METODOLÓGICOS}

Como estratégia de pesquisa, foram realizados estudos de casos múltiplos, o caso do curso de especialização em Negociação Coletiva e o do curso de graduação em Administração, os quais foram organizados em três etapas. Primeiramente, foi aplicado um questionário online - através do software Lime Survey - para os alunos dos cursos citados. Após, com base nos principais resultados observados na primeira fase da pesquisa, foi elaborado um questionário para os tutores que mediaram o processo de orientação do TCC. Este questionário também foi disponibilizado via web através do mesmo software. $\mathrm{Na}$ última fase da pesquisa foram efetuadas entrevistas semiestruturadas e pessoais com os professores orientadores do TCC. A análise dos dados coletados foi elaborada através da técnica de análise de conteúdo.

A pesquisa abrangeu: a) 120 alunos do curso de graduação em Administração, 284 alunos do curso de especialização em Negociação Coletiva (sendo que todos os que realizaram o TCC foram convidados a preencher o questionário disponibilizado via web); b) 7 professores orientadores (participantes de ambos os cursos) e, c) 20 tutores dos referidos cursos. A escolha dos participantes da pesquisa foi feita de acordo com a acessibilidade e interesse destes sujeitos em participarem, levando em conta os professores e tutores que tiveram uma atuação significativa em termos de quantidade de orientações.

\section{APRESENTAÇÃO E ANÁLISE DOS DADOS}

As citações mais representativas acerca do processo de construção do TCC são apresentadas na sequência.

\subsection{Perspectiva dos alunos}

Como principais resultados apresentados pelos alunos dos cursos pesquisados encontram-se os seguintes aspectos: administração do tempo; dificuldade de acesso ao campo de pesquisa e de acesso a materiais bibliográficos; dificuldade para redigir um texto no modelo de redação científica e problemas pessoais.

Adiante são ilustrados, através de depoimentos, os aspectos importantes relacionados à construção do TCC.

- Administração do tempo: A questão da dificuldade para realizar a administração do tempo e conciliar diferentes atividades foi admitida por diversos alunos:

O maior problema foi no momento de redação do quadro teórico, em que a leitura prévia de material sobre o tema do TCC é imprescindível, e como em um curso a distância, todas as disciplinas ocorrem em poucas semanas, sempre acumula muita leitura da matéria, fica complicado encontrar tempo para ler, além do exigido nas disciplinas 
correntes, o material para elaborar o quadro teórico do TCC (Aluno do curso de especialização).

- Dificuldade de acesso ao campo de pesquisa: os alunos dos dois cursos mencionaram como aspecto dificultador o acesso ao campo de pesquisa, desde a definição e autorização para ingresso ao campo e aplicação das entrevistas e /ou questionários, até a insegurança de se apresentar como pesquisador e conduzir a etapa de coleta de dados.

Minha maior dificuldade foi no desenvolvimento da pesquisa de campo e no desenvolvimento prático do trabalho. Tive vergonha de realizar as entrevistas, eu me senti inseguro nessa parte, não sabia se as ferramentas para coleta de dados atendiam as necessidades da minha pesquisa. Porém saliento que a orientação do tutor, nessa parte, foi imprescindível para o desenvolvimento do TCC (Aluno do curso de especialização).

- Dificuldade de acesso a materiais bibliográficos: a menção de dificuldade para ter acesso a materiais para pesquisa bibliográfica também foi recorrente. Apesar de terem sido disponibilizados digitalmente materiais com conteúdos curriculares aos alunos e de também ter sido organizado um acervo completo de materiais relacionados aos temas de pesquisa (como anais, livros, periódicos, teses e dissertações), muitos mencionaram preferência por livros e materiais impressos, que nem sempre estavam disponíveis, pelo fato dos alunos estarem alocados em polos distantes de grandes bibliotecas físicas.

A maior dificuldade foi conseguir livros, mesmo tendo à disposição a biblioteca do polo, eu não tinha como me deslocar até lá para buscar os livros. Essa foi a minha maior dificuldade. Imagine que você esteja elaborando o seu TCC e a biblioteca mais próxima de você esteja a 190 $\mathrm{km}$ de sua casa. Não existe fazer TCC sem ter acesso à uma biblioteca (Aluno do curso de graduação).

- Dificuldade para redigir um texto no modelo de redação científica: a dificuldade para construir textos no modelo de redação científica também foi mencionada pelos alunos. Alguns alegaram que o rigor científico exigido durante a construção do TCC não foi exigido em outras disciplinas do curso e que a "falta de treino" dificultou a construção textual no modelo requerido:

Senti falta de trabalhos nas disciplinas durante o curso que exigissem um formato adequado de escrita e padronização. Assim, quando chegasse o momento do TCC, com certeza a escrita seria mais suave e menos trabalhosa (Aluno do curso de graduação).

- Problemas Pessoais: dificuldades de cunho pessoal, tais como: doenças, mudança de residência, gravidez, divórcio, entre outros, também receberam destaque e teriam sido as principais justificativas utilizadas para solicitação de prorrogações dos prazos de entrega dos arquivos parciais ou da versão final do TCC, conforme pode ser observado no seguinte relato:

Tive problemas pessoais, que não gostaria de comentar, mas que surgiram justamente na fase mais crítica e trabalhosa do TCC e fizeram com que alguns prazos não fossem cumpridos por mim (Aluno do curso de especialização).

$\mathrm{Na}$ sequência serão apresentados os principais resultados apontados pelos tutores, no que concerne ao processo de construção do trabalho de conclusão de curso.

\subsection{Perspectiva dos tutores}

Os tutores foram questionados sobre a definição de seu papel enquanto mediadores do processo de orientação do trabalho de conclusão de curso e consideram que exercem um papel importante de suporte ao aluno nas diferentes fases da construção do TCC, sendo responsáveis por acompanhar e estimular os alunos no 
cumprimento das etapas previstas, esclarecendo dúvidas metodológicas, técnicas e didáticas, como pode ser observado no seguinte depoimento:

Além de dominar os aspectos técnicos e didáticos, o tutor deve ser um motivador, haja vista que em muitas fases a elaboração do TCC é uma tarefa solitária. O tutor deve ter a preocupação de não deixar o aluno com uma sensação de abandono, procurando mostrar-se presente e participante. Deve respeitar o ritmo dos alunos, mas concomitantemente deve cobrar para que o aluno respeite os prazos determinados pelo curso (Tutor do curso de especialização).

O acompanhamento tutorial é elemento fundamental e assegura o desenvolvimento dos eventos realizados em cursos EAD (NEVADO, 2005). Portanto, a tutoria deve ser reconhecida como estrutura de apoio ao aluno. Quando questionados sobre o papel do professor no processo de orientação do trabalho de conclusão de curso, os tutores parecem ratificar algumas das funções reconhecidas como as realizadas por eles próprios, mas alegam que os professores não se envolvem em todas as etapas da elaboração do trabalho e que o tutor acaba se sentindo sobrecarregado durante o processo. O relato seguinte caracteriza esta situação:

O professor é quem revisa o trabalho de maneira mais ampla, no sentido de conferir se há um alinhamento das partes (objetivos, metodologia, quadro teórico, etc.) e verifica se há coerência interna do texto. Ele orienta não só o aluno, mas também o tutor. O professor, portanto, deve propiciar (em razão da sua experiência) sugestões de abordagens para a ideia do aluno, e neste processo há também a formação do tutor enquanto um coorientador (Tutor do curso de graduação).

De fato, como afirma Lévy (1999), o papel do professor estará centrado mais no acompanhamento e na gestão das aprendizagens, incitando a troca de saberes, fazendo a mediação relacional, simbólica e personalizada dos percursos de aprendizagem. Por sua vez, os tutores trabalham na linha de frente, em contato direto com os alunos, atuando como mediadores do conhecimento nas disciplinas regulares e especialmente no processo de orientação do trabalho de conclusão de curso. Na opinião dos tutores, as maiores dificuldades encontradas pelos alunos durante a elaboração do TCC estão relacionadas ao rigor exigido pelo trabalho, que não é "treinado" com a mesma cobrança nas demais disciplinas regulares dos cursos, principalmente no que tange à adoção da redação científica e utilização das normas técnicas:

Falta de acesso à materiais e fontes de pesquisa, até mesmo a bibliotecas; falta de tempo para se dedicar ao TCC; falta de base sobre o que é um trabalho acadêmico, principalmente, pelo fato de estarem acostumados a tudo muito mastigado ao longo do curso e de repente precisarem fazer algo de autoria própria e individualmente. Esta questão deveria ter sido mais bem trabalhada nos alunos durante todo o curso, não só na fase do TCC (Tutor do curso de especialização).

Entre as sugestões que os tutores apresentam para melhorar o processo de orientação do trabalho final, destacam-se a necessidade de proximidade entre os tutores e professores, antes e durante a condução das orientações e do processo de construção do TCC, através de reuniões que discutam em conjunto as atribuições e papéis de cada um dos atores envolvidos. Eles também concordam que os alunos precisam ter consciência do rigor exigido num trabalho científico e que muitos alunos demoram para entender a estrutura de um TCC, apresentando dificuldades para compreender e atender os moldes solicitados. Uma solução apontada para melhorar este processo seria estimular os alunos a desenvolver atividades que exigem maior rigor científico ao longo do curso e não somente na etapa de construção do TCC. 


\subsection{Perspectiva dos professores orientadores}

$\mathrm{Na}$ opinião dos professores orientadores, o tutor atua em diferentes frentes na mediação da orientação do trabalho de conclusão de curso. O depoimento apresenta a opinião de um professor sobre a atuação do tutor:

O Tutor é uma figura muito importante nesse processo de orientação. Ele é de fundamental importância em vários sentidos. Ás vezes você pega um trabalho inicial, que ainda se apresenta de forma muito rudimentar, então o tutor lapida um pouco esse trabalho e vai conversando com o professor no sentido de orientar como é que o aluno pode conduzir, desde o estabelecimento da problemática, dos objetivos, enfim, o início do trabalho realmente. O tutor é essencial no sentido de lapidar, porque o trabalho ainda se apresenta muito incipiente nessa fase, então ajuda no processo de afunilar, para então, junto com o professor, estabelecer exatamente qual será o problema e os objetivos da pesquisa. Daí o professor entra, orientando a revisão da literatura e os tópicos a serem abordados no trabalho, mas o tutor é quem faz esta leitura inicial, de acordo com o que o orientador pede (Professor).

Alguns professores comentaram que nem todos os tutores sabem desempenhar adequadamente seu papel e apresentam falhas na execução de suas atribuições, porque não têm clareza sobre sua real função no processo de orientação do TCC.

Uma orientação incorreta vinda de um tutor é prejudicial, se o tutor disser para o aluno ir para um caminho "não certo", isso pode prejudicar o desenvolvimento e a própria conclusão da monografia. Como se tem visto, são muitas indicações inadequadas de literatura, técnicas de análise de dados inadequadas, forma de levantamento de dados errada. Quando o caminho começou errado, é muito complicado depois corrigir e é muito complicado também o orientador "desdizer" o tutor. Para o tutor precisa estar claro que o professor orientador sabe mais, ele tem mais experiência, então a palavra final, deve vir sempre do orientador e não do tutor (Professor).

Assim sendo, o tutor deve cumprir este papel fundamental, estimulando o aluno a se tornar sujeito crítico, epistemologicamente curioso, que constrói o conhecimento do objeto ou participa de sua construção. Os professores reconhecem que o tutor é uma figura importante no processo de construção e orientação do TCC. Consideram que tal processo exige que o tutor seja um articulador do diálogo entre o professor e o aluno, exercendo assim um papel de facilitador para que o aluno possa definir e "colocar no papel" aquilo que efetivamente quer fazer durante a pesquisa. Assim, os professores concordam que o tutor é essencialmente um interlocutor, porque a orientação efetivamente deve partir do professor orientador. Outro ponto que apresenta fragilidade é o processo de comunicação e interação entre alunos e professores orientadores. Geralmente, o contato é intermediado pelo tutor e neste fluxo pode haver falhas na comunicação, além disso, por não existirem encontros presenciais de orientação, os apontamentos das revisões parciais do TCC geralmente são descritos em arquivos trocados entre os alunos e os tutores. Também são passadas instruções via chat, e-mail e fórum de discussão, entretanto, por mais minuciosas que sejam estas considerações, essas dificilmente atendem o detalhamento e a clareza de questões que poderiam ser apontadas numa conversa direta com o aluno. Para minimizar falhas na comunicação, é importante o uso de ferramentas que possibilitem a interação em tempo real e, se possível a utilização de recursos com áudio e vídeo.

Uma coisa é você escrever algo sobre o que o aluno escreveu e ele simplesmente ler aquilo. Outra coisa é ter uma conversa direta, do tipo: "olha seu trabalho está bom aqui, não está bom ali, aqui precisa mudar". 
Essa é sistemática de orientação que eu gosto, que é trabalhar já com o projeto escrito, olhando exatamente o que o aluno quis dizer. Coisas que num trabalho de orientação no EAD fica mais difícil. Isso ainda é um problema, mas eu diria que num grau menor, porque vai diminuindo com o passar do tempo, até com a experiência que a gente vai adquirindo (Professor).

Por ser importante o desenvolvimento de disciplina em cursos EAD, para administração e cumprimentos de todas as atividades previstas no cronograma, a questão da autonomia do estudante também foi bastante mencionada pelos professores. A autonomia é um processo de amadurecimento e o professor, para auxiliar no desenvolvimento da autonomia dos alunos, precisa realizar e incentivar atividades que estimulem a tomada de decisão, para que os alunos sejam capazes de aprender a decidir com liberdade, assumindo as consequências desse ato (FREIRE, 1996).

Os principais aspectos comentados pelos professores acerca do processo de construção do trabalho de conclusão de curso foram a necessidade do desenvolvimento da autonomia do aluno no processo de ensino e aprendizagem, a importância da administração do tempo e da criação de uma rotina de estudos. Os professores também indicaram recomendações, enfatizando a importância da reestruturação do processo seletivo dos alunos e dos tutores e, sobretudo, a necessidade de reformular a forma de conduzir a apresentação das especificidades requeridas num trabalho científico, que geralmente são tratadas nas disciplinas de Metodologia, mas que, na opinião dos professores, precisa ser mais processual, incluindo eventos nos quais estas questões sejam pautadas em fases anteriores ao TCC. Contudo, os professores reconhecem que existem desafios, de ordem institucional, a serem superados, relacionados principalmente à quantidade de orientandos sob responsabilidade de cada professor e tutor, que interfere diretamente na qualidade das orientações oferecidas.

\section{CONSIDERAÇÕES FINAIS}

Tendo como parâmetro o objetivo alinhavado no início deste estudo, considerase que a trajetória da pesquisa apresenta contribuições significativas, as quais possibilitam uma reflexão acerca do que pode ser feito para otimizar o processo de orientação do TCC em cursos EAD. Neste estudo foi apresentada uma problemática percebida nos cursos realizados a distância, que exigem a elaboração e apresentação de um trabalho de conclusão de curso, problemática essa que é usual numa modalidade de ensino que vem se expandindo significativamente nas instituições de ensino brasileiras, mas que ainda não está sendo devidamente explorada nos estudos acadêmicos. Certos achados da pesquisa de campo mostraram-se contraditórios e ambíguos, principalmente se analisados à luz dos documentos disponibilizados a todos partícipes do curso (alunos, professores, tutores, coordenadores e equipe de apoio), como exemplo, o fato dos alunos reclamarem sobre a dificuldade de acesso a materiais bibliográficos, ao mesmo tempo em que uma série de materiais foram disponibilizados via web pela equipe pedagógica dos cursos pesquisados.

Em síntese, o principal aspecto apresentado pelos alunos, no que concerne ao processo de construção do TCC, está relacionado à escassez de tempo. Mesmo quando afirmam ter conseguido conciliar a realização de atividades acadêmicas, pessoais e profissionais, os alunos reconhecem que há um volume grande de trabalho na fase final do curso. De acordo com as informações levantadas, pode-se inferir como que esta dificuldade (de administrar o tempo) está associada, efetivamente, com a necessidade de autonomia e de autoresponsabilização por parte do aluno, tal como sugere Freire (1996). Os alunos também reconhecem a necessidade de estudarem e se dedicarem ainda mais na etapa de construção do TCC. De fato, o período final do curso exige uma carga maior 
de trabalho e, consequentemente, de disciplina e responsabilidade dos alunos; além disso, muitos não têm dimensão do rigor exigido no TCC e se deparam com um grande desafio nessa etapa conclusiva. Sugere-se, portanto, como condição essencial, que os alunos construam a concepção do que pretendem pesquisar no TCC, em fases anteriores à etapa final do curso. Seria oportuno que a disciplina de Metodologia Científica e a elaboração do projeto e do TCC, nas próximas edições dos cursos ou em outros cursos desta modalidade, sejam oferecidas de modo transversal, ou seja, poderiam acontecer simultaneamente às demais disciplinas regulares do curso e não concentradas na fase final, como agora acontece nos cursos investigados. Outros aspectos foram ponderados pelos alunos, como por exemplo: dificuldade para ter acesso ao campo a ser pesquisado e a materiais bibliográficos, redigir um texto científico, relacionamento com tutor, falta de motivação pessoal para elaborar o projeto, falta de orientação presencial (do professor e/ou tutor) e dificuldade para utilizar computadores e outros recursos tecnológicos.

Os tutores, por sua vez, admitem que atuam na mediação do processo de orientação do TCC, principalmente, para obterem experiência na área docente, considerando que a maioria destes profissionais está vinculada ao Programa de PósGraduação em Administração (PPGA) da Escola de Administração, como alunos de Mestrado ou Doutorado; portanto, vislumbram esta atuação na tutoria como oportunidade para ampliarem seus conhecimentos e melhorarem seu currículo para futuras oportunidades acadêmicas. Apesar de não serem reconhecidos institucionalmente como docentes, grande parte dos tutores participantes desta pesquisa considera que exerce papel de professor nos cursos investigados. De fato, alguns papéis acabam se misturando, tal como mostram Moore e Kearsley (2007), ao indicar teoricamente que o tutor é responsável pela elaboração do conteúdo do curso, enquanto que nos cursos investigados, esta é uma atribuição praticada pelo professor. Por outro lado, é o tutor o responsável pela avaliação preliminar do TCC, ou seja, é ele quem indica ao professor se o aluno está ou não apto para apresentar seu trabalho em banca. $\mathrm{Na}$ opinião dos tutores, os maiores problemas apresentados pelos alunos estão relacionados ao rigor exigido pelo TCC. Para eles, os alunos deveriam ser "treinados" ao longo do curso, com o mesmo grau de exigência em relação à aplicação e uso das normas técnicas e emprego de redação científica nos trabalhos de outras disciplinas regulares.

Na perspectiva dos professores, os principais aspectos relativos à construção do TCC para os alunos estão relacionados à necessidade do desenvolvimento da autonomia e de disciplina para a criação e cumprimento de uma rotina de estudos. Consideram ainda que também existem desafios a serem superados em relação à atuação dos tutores. Neste aspecto, foi enfatizada a necessidade de serem implementados processos seletivos mais rigorosos para definição da equipe de tutores atuantes em cada curso, que geralmente são escolhidos por conveniência (por serem mestrandos ou doutorandos do PPGA, por exemplo), os professores concordam que estes profissionais precisam ser adequadamente selecionados e devidamente capacitados para realizar suas funções. Outro fator que interfere na qualidade das orientações oferecidas é a grande quantidade de alunos sob responsabilidade de cada orientador, os professores reconhecem que esse número precisa ser reduzido, para que a orientação aconteça efetivamente de forma individual e personalizada.

Para finalizar, são apresentadas algumas diretrizes a título de recomendações às instituições de ensino que fazem uso da EAD e que tenham requisito a aprovação do aluno num trabalho de conclusão. Sugere-se (a) que as disciplinas componentes da matriz curricular do curso contemplem também critérios utilizados na avaliação e 
execução do trabalho final, estabelecendo controles de tempo e cronograma de atividades, para facilitar a organização e motivação dos alunos; (b) seja disponibilizado um guia de normas técnicas (de acordo com a ABNT) e exemplos de trabalhos de conclusão de curso de alunos que souberam aplicar tais normas adequadamente; (c) conscientização permanente sobre a importância da autonomia e da responsabilidade individual, por parte do aluno que estuda na modalidade a distância.

Alguns dos desafios apresentados podem ser minimizados pela equipe de coordenação do curso, professores orientadores e tutores; outros cabem exclusivamente ao aluno. Há alunos que alegam que não foram devidamente orientados e esclarecidos sobre o processo de construção do TCC, mas essa transferência de responsabilidade não pode ser uma justificativa para um insucesso na fase de encerramento do curso, mesmo depois de obter avaliações satisfatórias nas disciplinas regulares. Uma reflexão importante a ser feita é que vários dos aspectos mencionados como desafios para construção do TCC não parecem ser exclusivos de cursos ofertados na modalidade a distância. Existem situações que, de fato, precisam ser superadas, como a distância física entre os atores, por exemplo, entretanto, a necessidade de desenvolvimento de autonomia e a administração do tempo também são características essenciais aos alunos de cursos presenciais, portanto, um estudo comparativo acerca do mesmo tema, entre as duas modalidades de ensino é uma sugestão de tema para novas pesquisas.

\section{REFERÊNCIAS BIBLIOGRÁFICAS}

BELLONI, Maria Luiza. Educação a distância. Campinas, SP: Autores Associados, 1999.

CACHAPUZ, A. F. A universidade, a valorização do ensino e a formação dos seus docentes. In: SHIGUNOV NETO, A.; MACIEL, L.S.B. (Org.) Reflexões sobre a formação de professores. Campinas: Papirus, 2002. p.115-139.

FREIRE, Paulo. Pedagogia da autonomia: saberes necessários à prática educativa. 35. ed. São Paulo: Paz e Terra, 1996.

ISAIA, S. M. Desafios à docência superior: pressupostos a considerar. In: RISTOF, D.; LEAL, Viviane Pereira Lima Verde. O chat quando não é chato: o papel da mediação pedagógica em chats educacionais. In: ARAÚJO, Júlio César. Internet \& Ensino: novos gêneros, outros desafios. Rio de Janeiro: Lucerna, 2007.

LÉVY, Pierre. Cibercultura. Rio de Janeiro: Editora 34, 1999.

MOORE, Michael G.; KEARSLEY, Greg. Educação a distância: uma visão integrada. Tradução de Roberto Galman. São Paulo: Thomson Learning, 2007.

MORAN, José Manuel. Desafios na comunicação pessoal: gerenciamento integrado da comunicação pessoal, social e tecnológica. 3. ed. São Paulo: Paulinas, 2007.

NEVADO, Rosane Aragon de. Ambientes virtuais que potencializam as relações de ensino aprendizagem: ambientes virtuais de aprendizagem: do "ensino na rede" à "aprendizagem em rede". Novas Formas de Aprender: comunidades de aprendizagem: boletim, [Brasília, DF], n. 15, p. 14-20, ago. 2005. Disponível em: <http://tvbrasil.org.br/fotos/salto/series/151043NovasFormasAprender.pdf >. Acesso em: 21 out. 2012.

PACHANE, G. G. Teoria e prática na formação de professores universitários: elementos para discussão. In: RISTOF, D.; SAVEGNANI, P. Docência na educação superior. Brasília: Instituto Nacional de Pesquisas Educacionais Anísio Teixeira, 2006. 